\title{
Indoleamine 2,3-Dioxygenase (IDO)
}

\section{The Antagonist of Type I Interferon-Driven Skin Inflammation?}

\author{
Marina Scheler, ${ }^{*}$ Joerg Wenzel, ${ }^{*}$ Thomas Tüting, ${ }^{*}$ \\ Osamu Takikawa, ${ }^{\dagger}$ Thomas Bieber, ${ }^{*}$ and \\ Dagmar von Bubnoff* \\ From the Department of Dermatology,* Friedrich-Wilhelms- \\ University, Bonn, Germany; and the National Institute for \\ Longevity Science, ${ }^{\dagger}$ National Center for Geriatrics and \\ Gerontology, Aichi, Japan
}

Recent studies have provided evidence that a type I interferon (IFN)-driven immune response might play an important role in the pathogenesis of lichen planus (LP), an inflammatory disorder of the skin of unclear etiology. Plasmacytoid dendritic cells in affected skin from LP have been proposed to produce IFN- $\alpha / \beta$ locally, which leads to the expression of IFN-inducible chemokines such as IP10/CXCL10 in the epidermis. This chemokine recruits chemokine receptor CXCR3-expressing T-lymphocytes into the skin via CXCR3/IP10 interactions. Indoleamine 2,3-dioxygenase (IDO), which degrades tryptophan and suppresses T-cell proliferation, is induced by IFNs and other inflammatory cytokines. We show that type I IFN-mediated skin disorders, such as LP, strongly express IDO in lesional skin. This expression closely correlates to the expression of the highly specific type I IFN marker MxA. We further demonstrate that the $\mathrm{IDO}^{+}$cells in LP are large myeloid $\mathrm{CD}_{11 c^{+}} \mathrm{S100}^{+} \mathrm{CD}^{-} 8^{-}$dendritic cells. Accordingly, $\mathrm{CD}_{11 \mathrm{c}^{+}}$antigen-presenting cells significantly up-regulate IDO gene expression and intracellular IDO protein expression after stimulation with IFN- $\alpha$ in vitro. These findings reveal that both proinflammatory and counterregulatory mechanisms are operative in cutaneous lesions of LP. We propose that the balance of these mechanisms may be involved in the pathogenesis of this disorder. (Am J Pathol 2007, 171:1936-1943; DOI: 10.2353/ajpath.2007.070281)

Interferons (IFNs) are a family of cytokines with anti-proliferative, anti-viral, and immunomodulatory properties. Their action provides a critical link between innate and adaptive immune responses. ${ }^{1}$ In the skin, plasmacytoid dendritic cells (pDCs), which recognize pathogen-associated molecular patterns via Toll-like receptors, are presumed to be the main source of type I IFNs. ${ }^{2,3}$ Besides these physiological roles, type I IFNs are also involved in several pathological conditions. In particular, high expression of type I IFNs and IFN-inducible proteins was found in Th1-biased cell-mediated autoimmune skin diseases such as lichen planus (LP), lupus erythematosus (LE), dermatomyositis, and psoriasis. ${ }^{4-8}$ Recently, we and others provided evidence that the type I IFN-induced recruitment of skin homing lymphocytes via CXCR3/IP10 interaction participates in the skin inflammation in these disorders. ${ }^{9-13}$ The lesional inflammation is critically important for activating innate and adaptive immunity and is followed closely by the induction of anti-inflammatory mechanisms that protect tissue from collateral damage.

Indoleamine 2,3-dioxygenase (IDO) is an IFN-inducible enzyme that suppresses adaptive T-cell immunity by catabolizing the essential amino acid tryptophan from the cellular microenvironment. ${ }^{14,15}$ It is believed that T lymphocytes' deprivation of tryptophan and generation of biologically active metabolites along the tryptophan degradation pathway cause $\mathrm{T}$-cell apoptosis and preclude a T-cell response. ${ }^{16}$ IFN- $\alpha$ itself is supposed to be a weak inducer of IDO in antigen-presenting cells (APCs) but has an indirect effect on these cells through a yet to be defined $15-\mathrm{kDa}$ protein. ${ }^{16-18}$ This protein is a product of IFN- $\alpha$-stimulated APCs and lymphocytes and stimulates both IDO and IFN- $\gamma$ production. IFN- $\gamma$, in turn, is one of the most potent IDO inducers in cells of the immune system such as APCs as well as in local bystander cells such as in epithelial cells, lung cells, fibroblasts, and others. ${ }^{19}$ IDO expression increases when inflammation is induced by wounding, infection, or tumor growth. In in-

Supported by the University of Bonn (BONFOR grant) and the Deutsche Forschungsgemeinschaft (grant SFB 704, A15).

Accepted for publication September 5, 2007

Address reprint requests to Marina Scheler, Department of Dermatology, Friedrich-Wilhelms University, Sigmund Freud-Strasse 25, 53105 Bonn, Germany. E-mail: marina.scheler@ukb.uni-bonn.de. 
fection, IDO activity was first described as a mechanism for stopping the growth of microorganisms that otherwise depend on tryptophan. ${ }^{20}$ Another study pointed to a role for IDO in tumor escape: expression of IDO by immunogenic tumor cells in mice prevented rejection in preimmunized recipients. ${ }^{21}$ Furthermore, allergic asthma bronchiale in mice could be abrogated when IDO was induced in lung epithelial cells. ${ }^{22}$ Taken together, these observations in mice demonstrate that IDO can indeed have an immunoregulatory role. In humans, the role of IDO is less clear. IDO can be induced in many human cell types in vitro by stimulation with IFNs, lipopolysaccharide, tumor-necrosis factor- $\alpha$ (TNF- $\alpha$ ), Toll-like receptor ligands, or FceRl. ${ }^{15},{ }^{23-25}$ In human samples, direct evidence for the concomitant presence of inflammation and IDO is scarce. Therefore, the present study was designed to explore IDO expression in human skin. Our data demonstrate that IDO is highly expressed in lesional skin from patients with LP and other type I IFN-mediated diseases. We hypothesize that IDO may provide a counterplayer of the type I IFN-driven inflammation in the skin.

\section{Materials and Methods}

\section{Donors}

Lesional skin biopsies $(n=31)$ from different inflammatory skin disorders were analyzed. All skin biopsies included were taken for diagnostic purposes in stages of active skin disease before treatment. Patients suffered from chronic discoid lupus erythematosus (CDLE) $(n=9)$, LP $(n=5)$, cutaneous herpes simplex infection (HSV)-infection $(n=5)$, psoriasis vulgaris $(n=5)$, and atopic dermatitis (AD) $(n=$ 6). Control biopsies were taken from unaffected skin of patients undergoing surgery for skin tumors $(n=5)$. Informed consent was obtained from all donors. The study was performed according to local ethical guidelines and approved by the local regulatory committee.

\section{Histology and Immunohistology}

Serial sections were prepared from formalin-fixed, paraffin-embedded skin biopsies. Standard hematoxylin and eosin staining and periodic acid-Schiff reactions were performed for diagnostic purposes. In situ IFN- $\alpha / \beta$ production was evaluated by immunostaining for $\mathrm{M} \times \mathrm{A}$ ( $\mathrm{mAb}$ M143, dilution 1:100; a kind gift from Dr. Haller, University of Freiburg, Freiburg, Germany), an IFN- $\alpha / \beta$-inducible antiviral intracellular protein well established as a surrogate marker for local IFN- $\alpha / \beta$ production, as described before. ${ }^{26,27}$ Mouse anti-human IDO antibody (IgG1 Ab, 1:150; as described previously) ${ }^{28,29}$ labeling was performed on paraffin-embedded tissue sections (4 $\mu \mathrm{m})$ after heat pretreatment as described in detail elsewhere. ${ }^{27,30}$ Appropriate isotype-matched controls were included. Visualization was performed using the LSAB2 staining kit (DAKO, Hamburg, Germany) with fast red as chromogen, for sequential double staining combined with the Envision System (DAKO) with the chromogen diaminobenzidine (brown). Results were evaluated on blinded specimens by two experienced dermatopathologists (J.W. and T.T.) independently. IDO ${ }^{+}$cells were counted per three representative high-power fields (HPFs, $\times 200)$ in a microscope (BH-2 microscope and DF 70 camera; both from Olympus Europe $\mathrm{GmbH}$, Hamburg, Germany), and the mean IDO ${ }^{+}$cells per three HPFs was calculated.

The expression of MxA in the epidermis and in the inflammatory infiltrate was scored semi quantitatively $(0=$ no expression; $+=$ weak expression; $++=$ fair expression; $+++=$ strong expression) within the same three HPFs used for IDO detection, and the mean lesional MxA expression was calculated.

\section{Immunofluorescence Staining}

Immunofluorescence double staining was performed using formalin-fixed, paraffin-embedded sections after heat antigen retrieval following standard protocols. The following primary monoclonal antibodies (mAbs) were used: anti-IDO mAb (AHP833, dilution 1:200; Serotec, Düsseldorf, Germany), anti-CD11c mAb (dilution 1:10; Novocastra, Newcastle, UK), anti-CD68 mAb (dilution 1:40, Novocastra), anti-CD1a mAb (undiluted; Immunotech, Marseille, France), anti-S100 mAb (dilution 1:1200, DAKO), anti-CD123 mAb (dilution 1:50; Becton-Dickinson, San Jose, CA), and antiCD3 mAb (undiluted; Beckman Coulter, Krefeld, Germany). As secondary $\mathrm{Ab}$ we used a fluorescein isothiocyanate (FITC)-conjugated donkey anti-sheep-IgG (dilution 1:100, Serotec) to detect the IDO mAb, and to detect the S100 $\mathrm{mAb}$ we used a CY3-conjugated goat anti-rabbit-lgG (dilution 1:50; Zymed, München, Germany). For the other primary Abs, we used a CY3-conjugated goat anti-mouse IgG (1:200, Zymed).

\section{Isolation of Peripheral Blood Monocytes and T Cells}

All blood samples were obtained after informed consent from healthy volunteers $(n=5)$ in accordance with the local ethics committee. Monocytes were isolated from peripheral blood with a density gradient protocol using Nycoprep (Nycomed, Oslo, Norway). Briefly, red blood cells were separated from plasma by sedimentation from ethylenediaminetetraacetic acid blood with one-tenth (w/v) $6 \%$ dextran 500 in $0.9 \% \mathrm{NaCl}$. Plasma was layered over Nycoprep and centrifuged for 20 minutes at $600 \times g$. After separation, the interphase and upper part of the Nycoprep were collected and washed three times. Monocyte isolation was confirmed by CD14 expression and was $>90 \%$.

$T$ cells were isolated from heparin blood with a density gradient protocol using Lymphoprep (Nycomed). After the blood was diluted 1:1 with phosphate-buffered saline (PBS), suspended cells were overlayed on prior undiluted blood volume of Lymphoprep. Peripheral blood mononuclear cells were isolated as interface cells after density gradient centrifugation ( 30 minutes at $2000 \times g$ at room temperature). T cells were then purified from peripheral blood mononuclear cells using a nylon wool column. 

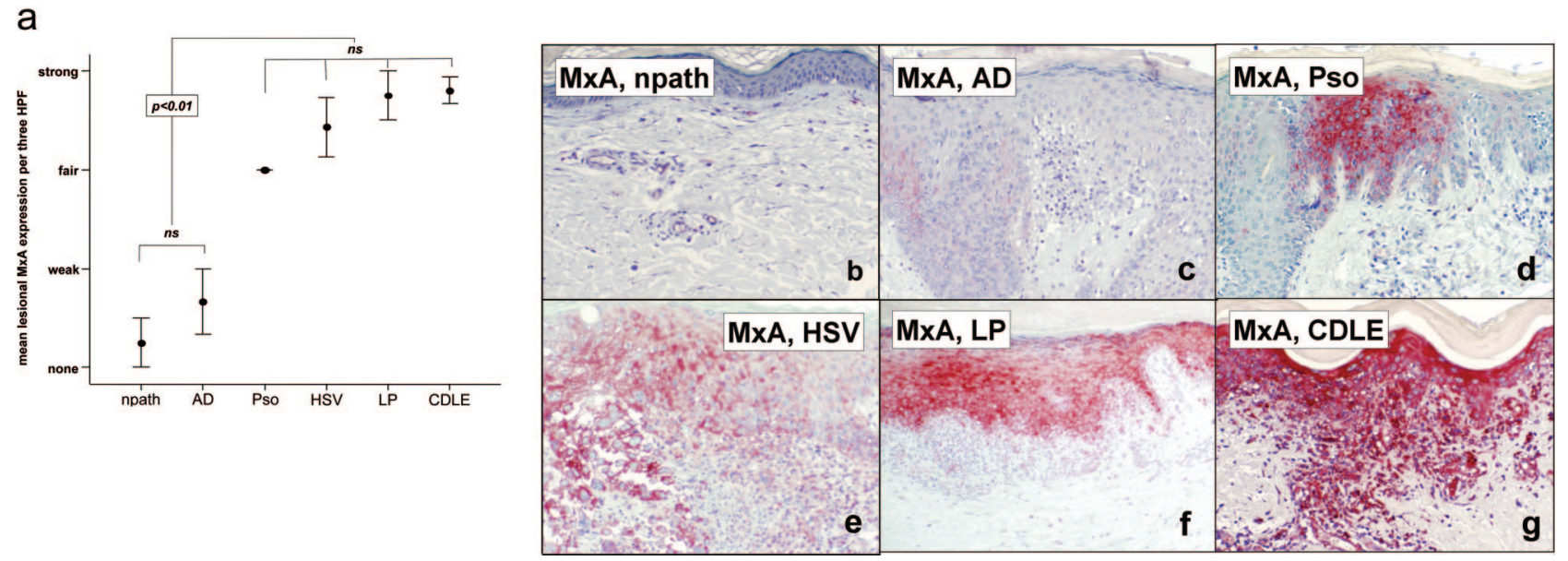

Figure 1. MxA is strongly up-regulated in type I IFN-mediated skin disorders. a: Lesional MxA expression in normal skin (npath), AD, psoriasis (Pso), HSV, LP, and CDLE was scored semiquantitatively. b-g: Representative stainings with MxA in skin biopsies from the different diseases. Immunohistology was performed on paraffin-embedded skin biopsies using the monoclonal antibody MxA-M143 with the LSAB2 system for visualization (chromogen, fast red).

\section{In Vitro Stimulation of Monocytes and T Cells}

Isolated peripheral blood monocytes and T cells (each $1 \times 10^{6} / \mathrm{ml}$ RPMI 1640) were stimulated for 24 hours with $1000 \mathrm{U} / \mathrm{ml}$ IFN- $\alpha$ (recombinant interferon alpha-2b, INTRON A; Essex Pharma, Munich, Germany) and $100 \mathrm{U} / \mathrm{ml}$ IFN- $\gamma$ (R\&D Systems, Wiesbaden-Nordenstadt, Germany), respectively. Unstimulated controls were included. The cells were washed twice before staining. Stimulations were done with five different donors.

\section{Immunostaining of Peripheral Blood Monocytes and $T$ Cells}

Peripheral blood monocytes or T cells from healthy donors $(n=5)$ were stained by using a 96-well roundbottom plate $\left(10^{5}\right.$ cells/well). Monocytes and T cells were washed three times with PBS and incubated for 15 minutes with 7-amino-actinomycin D to exclude dead cells from analysis. Intracellular staining with anti-IDO Ab was done as follows: after fixation and permeabilization with $4 \%$ formaldehyde and saponine buffer, respectively, cells were stained with anti-IDO mAb $(2.5 \mu \mathrm{g} / \mathrm{ml})$ for 20 minutes, followed by FITC-labeled $F\left(a b^{\prime}\right)_{2}$ of goat-antimouse Ab (GaM/FITC) from Jackson ImmunoResearch Laboratories (West Grove, PA). After washing with saponine buffer and PBS/BSA/Na-Azid, the extracellular staining for monocytes was performed with anti-CD14 mAb (mouse IgG2b, Becton-Dickinson) and anti-CD11c mAb. T cells were stained with anti-CD3 mAb. Analysis of cells was performed with a FACS Canto cytometer (BectonDickinson, Heidelberg, Germany). Monocytes and T cells were gated on forward and sideward scatter.

\section{Reverse Transcriptase-Polymerase Chain Reaction (RT-PCR)}

Total RNA was extracted from monocytes using Trizol (Invitrogen, Carlsbad, CA) according to the manufacturer's instructions. Reverse transcription was done with 1 $\mu \mathrm{g}$ of total RNA. The resulting CDNA was amplified by PCR using IDO sense (5'-CTTCCTGGTCTCTCTATTGG$3^{\prime}$ ) and antisense (3'-GAAGTTCCTGTGAGCTGGTG-5') primers. Amplification was performed on a Perkin-Elmer GeneAmp PCR system 9600 thermocycler (Applied Biosystems, Weiterstadt, Germany). $\beta$-Actin was used to normalize specific PCR amplifications. The PCR cycle number for the detection of IDO was 26. PCR fragments were separated on $1 \%$ agarose gels, visualized using ethidium bromide staining and analyzed by digital image analysis using the WinCam system (Cybertech, Berlin, Germany).

\section{Statistical Analysis}

Computer-based statistical analyses were performed using SPSS software (version 12; SPSS, Chicago, IL). The nonparametrical Mann-Whitney U-test was used to compare the expression of IDO and MxA in different skin disorder subsets and healthy controls. Correlation analysis was done by Spearman's $\rho$. Probabilities $<0.05^{\star}$ were considered to be significant, $P$ values $<0.01^{\star \star}$ as highly significant.

\section{Results}

\section{IDO Is Strongly Expressed in Lesions of Type I IFN-Mediated Skin Disorders}

Earlier studies provided evidence that type I IFNs participate in the pathogenesis of several Th1-based inflammatory skin disorders such as LP, LE, and psoriasis. ${ }^{9,13,31,32}$ We analyzed the concomitant expression of the highly specific type I IFN marker MxA and the enzyme IDO in adjacent tissue sections from several skin disorders. A strong $(+++)$ MxA expression was found in all donor samples from inflammatory lesions of LP, CDLE, and HSV infection (Figure 1a). Psoriatic skin samples fairly $(++)$ expressed MxA whereas in AD MxA expres- 
a

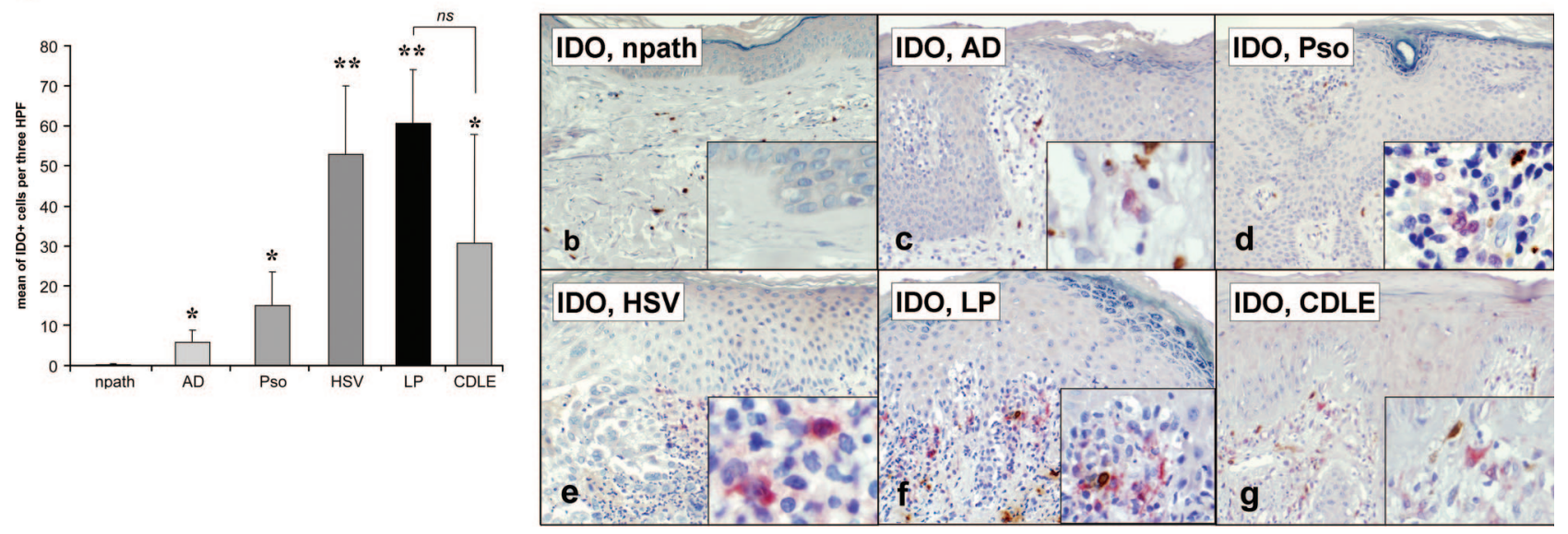

Figure 2. IDO is strongly expressed in lesions of type I IFN-mediated skin disorders. a: Lesional IDO expression in normal skin (npath), AD, psoriasis (Pso), HSV, $\mathrm{LP}$, and CDLE. IDO ${ }^{+}$cells were counted per three HPFs, and the mean was calculated. b-g: Representative immunohistological pictures of IDO expression. Immunohistology was performed on paraffin-embedded skin biopsies using a monoclonal anti-IDO Ab with the LSAB2 system for visualization (chromogen, fast red). Lesional mast cells showed in some cases an unspecific reactivity despite blocking procedures and were therefore counterstained with anti-chymase, using the Envision system with diaminobenzidine as chromogen (brown). Original magnifications, $\times 200$.

sion ranged from very low to weak $(+)$. In healthy control biopsies, MxA expression was nearly absent. MxA expression was seen in the epidermis as well as in the inflammatory dermal infiltrate. Figure 1, b-g, depicts representative findings on MxA expression in the different diseases.

To investigate whether the local production of IFN- $\alpha / \beta$ is able to induce IDO in the skin, we quantitatively evaluated the number of $\mathrm{IDO}^{+}$cells in adjacent tissue sections from the various disorders by immunohistochemistry (Figure 2a). Interestingly, the highest numbers of $\mathrm{IDO}^{+}$cells were seen in LP and HSV skin lesions, followed by tissue from CDLE. In psoriasis, moderate IDO+ cells were seen whereas in AD only few cells expressed IDO. Normal control tissue was virtually negative for IDO. Remarkably, IDO ${ }^{+}$cells were exclusively seen within the dermal inflammatory infiltrate and not in the epidermis (Figure 2, b-g). In contrast to human placenta, for example, where endothelial cells do express IDO, ${ }^{33}$ stromal elements were negative for IDO in all our investigated samples (see enlarged pictures of Figure 2, b-g).

Subsequently, we performed statistical investigations to strengthen our hypothesis of an influence of the type I IFN system on the lesional IDO expression. For this, MxA expression and $\mathrm{IDO}^{+}$cells of each sample were investigated and correlated to the entire samples independently of the specific diseases (Figure 3). MxA expression was not always in every single specimen but in significantly more specimens was associated with a fair to high IDO expression. The association of the lesional IDO production with the expression of the type I IFN marker MxA was analyzed using computer-based methods to calculate Spearman's $\rho$. These analyses revealed a direct, highly significant correlation between the expression of IDO and MxA ( $\rho=0.53, P<0.01)$ in the investigated specimens, which supports our hypothesis.

\section{Myeloid $C D 11 \mathrm{C}^{+} \mathrm{S} 100^{+} \mathrm{CD68} 8^{-} \mathrm{DCs}$ Are the IDO-Expressing Cells in Lesions from LP and}

\section{Psoriasis}

To characterize further the nature of $\mathrm{IDO}^{+}$cells, we performed double-staining immunofluorescence using the IDO mAb in combination with multiple markers (Figure 4). Staining with a specific Ab to the myeloid marker CD11c revealed that virtually all $\mathrm{IDO}^{+}$cells were of myeloid origin. In addition, IDO ${ }^{+}$cells were also strongly positive for S100, a specific marker for DCs. As expected from these stainings, $\mathrm{IDO}^{+}$cells were negative for the macrophage marker CD68 and were clearly larger than $\mathrm{CD}^{+}$ macrophages. Remarkably, epidermal CD1a ${ }^{+}$DCs (ie, Langerhans cells) did not express IDO. Unexpectedly, $\mathrm{CD}_{123^{+}}$pDCs were negative for IDO although present in significant amounts in lesions from LP. Further, the nu-

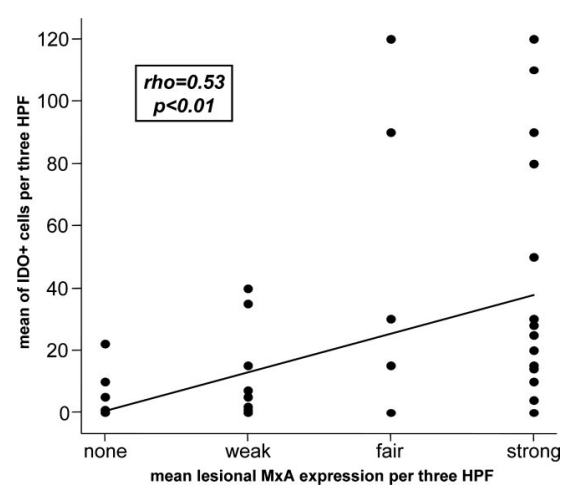

Figure 3. Lesional IDO production correlates with the expression of MxA The association of lesional $\mathrm{IDO}^{+}$cells (calculated by the mean of three representative HPFs) with the expression of the type I IFN marker MxA (scored semiquantitatively by the mean of the same three HPFs used for IDO detection) is shown. Correlation analysis was done by Spearman's $\rho$. Probabilities $<0.05^{*}$ were considered to be significant, $P$ values $<0.01^{* *}$ as highly significant. Original magnifications, $\times 200$. 


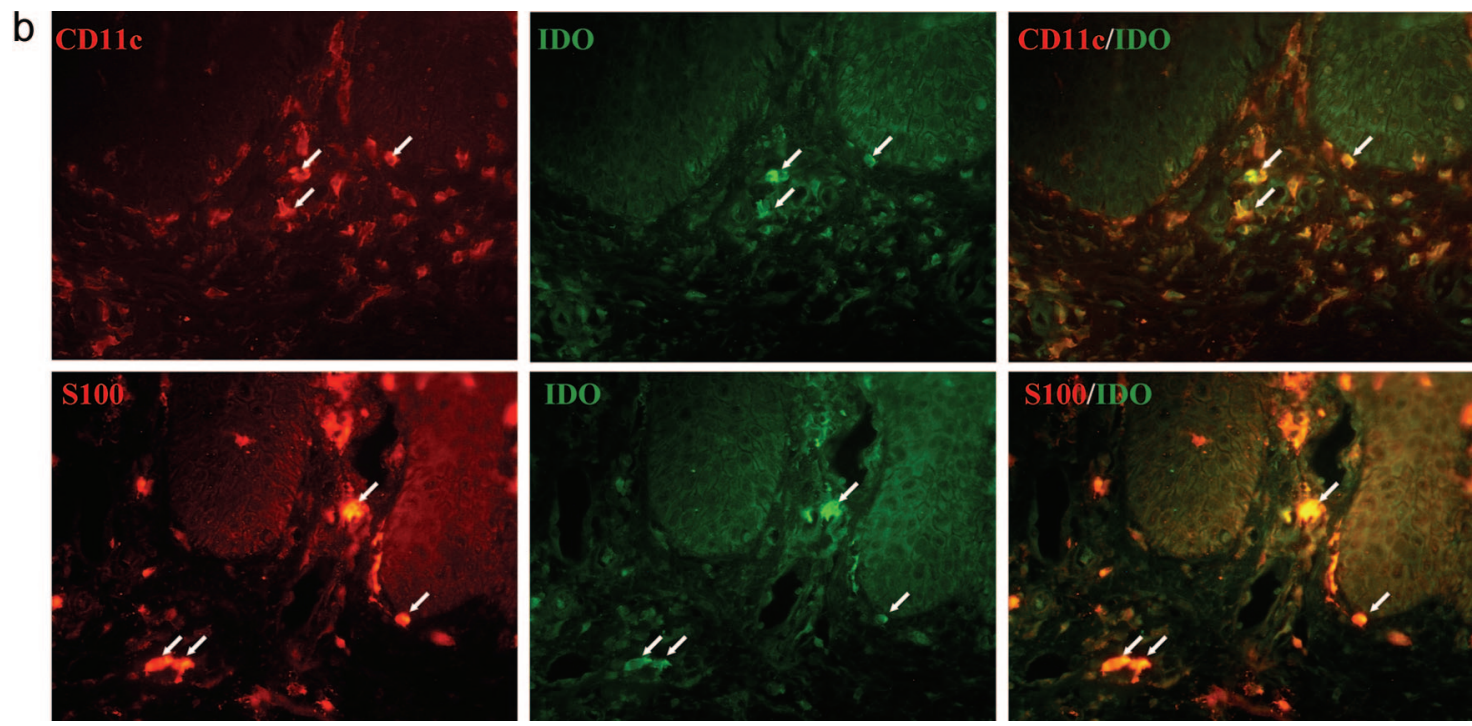

Figure 4. Continued.

merous $\mathrm{CD}^{+} \mathrm{T}$ cells were clearly negative for IDO. Here, the presence of large veiled cells just adjacent to the numerous small round $T$ cells can be nicely seen. In summary, large myeloid $\mathrm{CD} 11 \mathrm{c}^{+} \mathrm{S} 100^{+} \mathrm{CD}_{6} 8^{-} \mathrm{DCs}$, and not $\mathrm{CD}_{123^{+}}$pDCs, are the IDO-expressing cells in LP and psoriasis.

\section{IFN- $\alpha$ and IFN- $\gamma$ Induce IDO in Peripheral Blood Monocytes but Not in T Cells}

To establish further that $\mathrm{CD} 11 \mathrm{c}^{+}$APCs induce IDO expression in response to type I IFNs, we tested the IDO gene transcription and expression in isolated monocytes. Figure $5 \mathrm{a}$ demonstrates that unstimulated $\mathrm{CD} 11 \mathrm{c}^{+}$ monocytes isolated from healthy individuals do not show IDO gene transcription as shown by RT-PCR using IDOspecific primers. In contrast, a strong RT-PCR signal for IDO was detected after treatment of monocytes with IFN- $\alpha$. To confirm the induction of IDO protein by type I IFNs and also by IFN- $\gamma$, we analyzed the intracellular expression of the IDO protein in human APCs after stimulation with IFN- $\alpha$ and IFN- $\gamma$ in vitro. Monocytes from five different healthy donors were isolated from peripheral

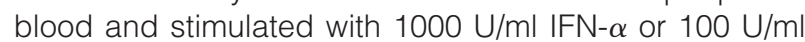
IFN- $\gamma$ as described in Materials and Methods. Although unstimulated control monocytes did not show significant IDO protein expression, IFN- $\alpha$ - and IFN- $\gamma$-stimulated $\mathrm{CD} 14^{+} \mathrm{CD} 11 \mathrm{C}^{+}$monocytes displayed a significant expression of the intracellular protein IDO (Figure 5b). In contrast, freshly isolated $\mathrm{CD}^{+} \mathrm{T}$ cells did not express IDO after in vitro stimulation with IFN- $\alpha$ and IFN- $\gamma$, consistent with our in vivo data.

\section{Discussion}

In the present study we provide evidence for a significant expression of the IDO protein in skin disorders associ-
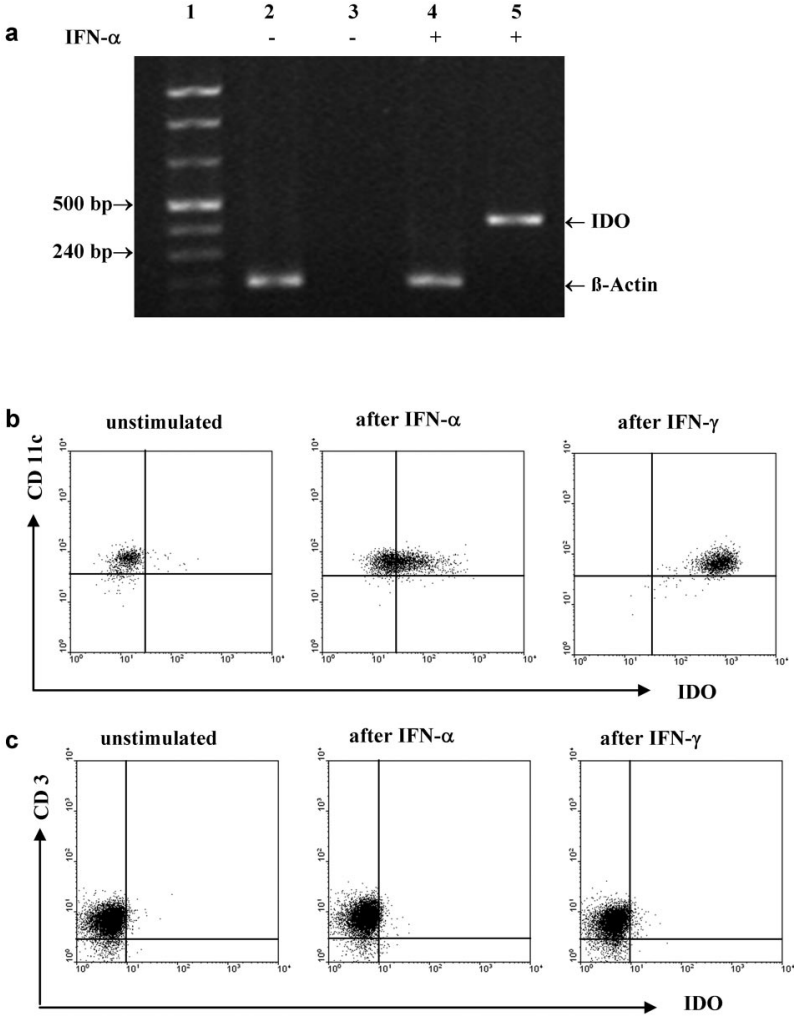

Figure 5. IDO is induced in IFN- $\alpha$ - and IFN- $\gamma$-stimulated monocytes but not in T cells. a: RT-PCR of IDO gene transcript expression from unstimulated and stimulated monocytes. Stimulation was performed with 1000 $\mathrm{U} / \mathrm{ml}$ IFN- $\alpha$ for 24 hours. In stimulated monocytes, a strong RT-PCR signal was detected whereas unstimulated monocytes did not up-regulate IDO gene transcription. Flow cytometric analysis of monocytes (b) and $\mathrm{T}$ cells (c) with and without IFN- $\alpha$ or IFN- $\gamma$ stimulation ( 24 hours) was performed with a monoclonal mouse-anti-human IDO Ab followed by a FITC-labeled anti-mouse secondary Ab. Cells were counterstained with anti-CD14 and anti-CD11c (monocytes) or anti-CD3 (T cells). Monocytes and $\mathrm{T}$ cells were gated by a combination of forward and side scatter. Dead cells were excluded from analysis. One donor is shown as representative for all five donors. 
ated with type I IFN. The strongest production of IDO was seen in LP, followed by HSV-infected tissue, and CDLE lesions. In all these diseases, $\mathrm{IDO}^{+}$cells can be found exclusively in the dermal inflammatory infiltrate and not in the epidermis. This is remarkable because the pathology of $A D$, psoriasis, or HSV infection also involves the epidermis and epidermal MxA expression is strong. There might be two reasons for this. Recently, our group demonstrated that human keratinocytes do not respond with IDO protein activity on stimulation with IFNs and are thus negative for this protein despite the presence of inflammatory stimuli. ${ }^{28}$ In contrast, highly enriched human epidermal LCs were found able to respond with IDO protein activity on stimulation with IFN- $\gamma$ in vitro. Therefore, it is possible that IFNs, eg, in the course of LP inflammation, act to induce IDO in some APC populations but not in the others, or the level of IFNs reached in the epidermal lesions are too low to induce IDO in LCs.

We further demonstrate that in lesions from LP and psoriasis, large myeloid $\mathrm{CD} 11 \mathrm{c}^{+} \mathrm{S} 100^{+} \mathrm{CD} 68^{-} \mathrm{DCs}$, and not pDCs, are the dermal IDO-expressing cells. Further, our analyses revealed a strong in vitro induction of IDO in $\mathrm{CD} 14^{+} \mathrm{CD} 11 \mathrm{C}^{+}$monocytes after stimulation with IFN- $\alpha$ and IFN- $\gamma$. These findings suggest a new function of myeloid DCs in autoimmune skin diseases. In addition to their important role for the induction of specific immunity, these DCs seem to have tolerizing properties as a consequence of IDO expression.

Type I IFNs are crucially involved in the recruitment of inflammatory $\mathrm{CXCR}^{+}$lymphocytes in LP, probably as a result of IFN $\alpha / \beta$-dependent up-regulation of the chemokine IP10/CXCL10 in the skin. ${ }^{11}$ In accordance with this, we have recently demonstrated a large number of plasmacytoid DCs (pDCs) in LP skin lesions, which are a major source of lesional type I IFN production in LP. ${ }^{11}$ We show here that type I and type II IFNs are able to induce IDO in CD11 $\mathrm{C}^{+}$APCs in vitro. It is very likely that, also in inflammatory skin from LP, IFN- $\alpha$ from $\mathrm{pDCs}$ induces IFN- $\gamma$ from T cells, ${ }^{34,35}$ both of which promote the function of bystander myeloid DCs to strongly express IDO. ${ }^{36}$ Moreover, it has been recently reported, that in mice, IDO itself is required for the production of IFN- $\alpha$ after ligation of $\mathrm{B} 7$ molecules on $\mathrm{CD} 19^{+} \mathrm{DCs} .{ }^{37}$ These results suggest a bi-directional feedback loop on IDO induction through IFN- $\alpha$, which is most likely sustained by IFN- $\gamma$.

Recent work has demonstrated a highly complex role for IDO in immunoregulation in infection, pregnancy, autoimmunity, transplantation, allergy, and neoplasia. ${ }^{19,21,38,39}$ Because IDO induction represents a ubiquitous and highly conserved inflammatory immune response pattern, the tolerogenic outcome of it may be good or bad for the host, depending on the disease. For example in cancer, IDO expression in APCs or the tumor cells themselves is one possible mechanism by which the immune system might be able to acquire tolerance toward tumor antigens. ${ }^{21}$ Moreover, in viral infections including HIV, there is a lot of local and systemic IDO activity. ${ }^{40}$ This IDO activity has been suggested to be responsible for cachexia, dementia, diarrhea, and possibly immunosuppression in these patients.
In contrast, apoptosis of potentially autoreactive lymphocytes by IDO-expressing DCs, activated by IFN- $\alpha$ and IFN- $\boldsymbol{\gamma}$, might represent a crucial means of maintaining peripheral tolerance during inflammation. ${ }^{19}$ These IDO-expressing DCs might thus add to discriminate between self and nonself during active autoimmune disease. It has been suggested, that type I IFNs are key factors when tolerance is lost and autoreactivity appears. ${ }^{41}$ Although IFN type I is often associated or paralleled with the severity of the autoimmune disease, there are the first examples for the concomitant induction of IDO in these diseases such as in systemic lupus erythematosus. ${ }^{42}$ IFN- $\alpha$ was shown to be a necessary upstream inducer of IDO in some mouse pDC subsets after engagement of specific molecules on these cells. ${ }^{43-45}$ These data suggest that, in most conditions involving pDCs, IFN- $\alpha$ will have an obligatory and immediate role in IDO induction. Further, in nonobese diabetic mice, it was found that an impaired tryptophan catabolism is causative to the defective tolerance. ${ }^{38}$ Thus, in autoimmune diseases, IDO induction seems to be part of an integrated response for preventing excessive local inflammation and preventing further autoimmune damage. Accordingly, the close association and concomitant expression of IDO and inflammatory stimuli such as type I IFNs that were seen here in lesional skin of LP suggests that IDO expression can be seen as a counterregulatory mechanism directed at dampening the inflammation.

\section{Acknowledgments}

We thank G. Häcker, M.D., Institute for Medical Microbiology, Immunology, and Hygiene, Technical University of Munich, Munich, Germany, for critical reading of the manuscript; S. Zahn, H. Wilms, S. Mikus, and A. Schmischke for technical assistance; and Prof. Otto Haller (University of Freiburg, Freiburg, Germany) for the gift of anti-MxA antibody M143.

\section{References}

1. Tough DF: Type I interferon as a link between innate and adaptive immunity through dendritic cell stimulation. Leuk Lymphoma 2004, 45:257-264

2. Hochrein H, Schlatter B, O'Keeffe M, Wagner C, Schmitz F, Schiemann M, Bauer S, Suter M, Wagner H: Herpes simplex virus type-1 induces IFN-alpha production via Toll-like receptor 9-dependent and -independent pathways. Proc Natl Acad Sci USA 2004, 101:11416-11421

3. Bogdan C: The function of type I interferons in antimicrobial immunity Curr Opin Immunol 2000, 12:419-424

4. Santoro A, Majorana A, Roversi L, Gentili F, Marrelli S, Vermi W, Bardellini E, Sapelli P, Facchetti F: Recruitment of dendritic cells in oral lichen planus. J Pathol 2005, 205:426-434

5. Farkas L, Beiske K, Lund-Johansen F, Brandtzaeg P, Jahnsen FL: Plasmacytoid dendritic cells (natural interferon-alpha/beta-producing cells) accumulate in cutaneous lupus erythematosus lesions. Am J Pathol 2001, 159:237-243

6. Rönnblom L, Eloranta ML, Alm GV: Role of natural interferon-alpha producing cells (plasmacytoid dendritic cells) in autoimmunity. Autoimmunity 2003, 36:463-472

7. Greenberg SA, Pinkus JL, Pinkus GS, Burleson T, Sanoudou D, Tawil $\mathrm{R}$, Barohn RJ, Saperstein DS, Briemberg HR, Ericsson M, Park P, 
Amato AA: Interferon-alpha/beta-mediated innate immune mechanisms in dermatomyositis. Ann Neurol 2005, 57:664-678

8. van der Fits L, van der Wel LI, Laman JD, Prens EP, Verschuren MC: In psoriasis lesional skin the type I interferon signaling pathway is activated, whereas interferon-alpha sensitivity is unaltered. J Invest Dermatol 2004, 122:51-60

9. Wenzel J, Worenkamper E, Freutel S, Henze S, Haller O, Bieber T, Tuting T: Enhanced type I interferon signalling promotes Th1-biased inflammation in cutaneous lupus erythematosus. J Pathol 2005, 205:435-442

10. Meller S, Winterberg F, Gilliet M, Muller A, Lauceviciute I, Rieker J, Neumann NJ, Kubitza R, Gombert M, Bunemann E, Wiesner U, Franken-Kunkel P, Kanzler H, Dieu-Nosjean MC, Amara A, Ruzicka T, Lehmann P, Zlotnik A, Homey B: Ultraviolet radiation-induced injury, chemokines, and leukocyte recruitment: an amplification cycle triggering cutaneous lupus erythematosus. Arthritis Rheum 2005, 52:1504-1516

11. Wenzel J, Scheler M, Proelss J, Bieber T, Tuting T: Type I interferonassociated cytotoxic inflammation in lichen planus. J Cutan Pathol 2006, 33:672-678

12. Wenzel J, Uerlich M, Worrenkamper E, Freutel S, Bieber T, Tuting T: Scarring skin lesions of discoid lupus erythematosus are characterized by high numbers of skin-homing cytotoxic lymphocytes associated with strong expression of the type I interferon-induced protein MxA. Br J Dermatol 2005, 153:1011-1015

13. Wenzel J, Peters B, Zahn S, Birth M, Hofmann K, Kusters D, Tomiuk S, Baron JM, Merk HF, Mauch C, Krieg T, Bieber T, Tuting T, Bosio A: Gene expression profiling of lichen planus reflects CXCL9+-mediated inflammation and distinguishes this disease from atopic dermatitis and psoriasis. J Invest Dermatol [Epub ahead of print]

14. Mellor A: Indoleamine 2,3 dioxygenase and regulation of $\mathrm{T}$ cell immunity. Biochem Biophys Res Commun 2005, 338:20-24

15. Wingender G, Garbi N, Schumak B, Jungerkes F, Endl E, von Bubnoff D, Steitz J, Striegler J, Moldenhauer G, Tuting T, Heit A, Huster KM, Takikawa O, Akira S, Busch DH, Wagner H, Hammerling GJ, Knolle PA, Limmer A: Systemic application of CpG-rich DNA suppresses adaptive T cell immunity via induction of IDO. Eur J Immunol 2006, 36:12-20

16. Terness P, Bauer TM, Rose L, Dufter C, Watzlik A, Simon H, Opelz G: Inhibition of allogeneic $\mathrm{T}$ cell proliferation by indoleamine 2,3-dioxygenase-expressing dendritic cells: mediation of suppression by tryptophan metabolites. J Exp Med 2002, 196:447-457

17. Maneglier B, Rogez-Kreuz C, Spreux-Varoquaux O, Malleret B, Therond P, Samah B, Drouet I, Dormont D, Advenier C, Clayette P. Comparative effects of two type I interferons, human IFN-alpha and ovine IFN-tau on indoleamine-2,3-dioxygenase in primary cultures of human macrophages. Fundam Clin Pharmacol 2007, 21:29-34

18. Recht M, Borden EC, Knight Jr E: A human 15-kDa IFN-induced protein induces the secretion of IFN-gamma. J Immunol 1991, 147:2617-2623

19. Grohmann U, Fallarino F, Puccetti P: Tolerance. DCs and tryptophan: much ado about IDO. Trends Immunol 2003, 24:242-248

20. MacKenzie CR, Langen R, Takikawa O, Daubener W: Inhibition of indoleamine 2,3-dioxygenase in human macrophages inhibits interferon-gamma-induced bacteriostasis but does not abrogate toxoplasmastasis. Eur J Immunol 1999, 29:3254-3261

21. Uyttenhove C, Pilotte L, Theate I, Stroobant V, Colau D, Parmentier N, Boon T, Van den Eynde BJ: Evidence for a tumoral immune resistance mechanism based on tryptophan degradation by indoleamine 2,3-dioxygenase. Nat Med 2003, 9:1269-1274

22. Hayashi T, Beck L, Rossetto C, Gong X, Takikawa O, Takabayashi K, Broide DH, Carson DA, Raz E: Inhibition of experimental asthma by indoleamine 2,3-dioxygenase. J Clin Invest 2004, 114:270-279

23. Braun D, Longman RS, Albert ML: A two-step induction of indoleamine 2,3 dioxygenase (IDO) activity during dendritic-cell maturation. Blood 2005, 106:2375-2381

24. Fujigaki S, Saito K, Sekikawa K, Tone S, Takikawa O, Fujii H, Wada H, Noma A, Seishima M: Lipopolysaccharide induction of indoleamine 2,3-dioxygenase is mediated dominantly by an IFN-gamma-independent mechanism. Eur J Immunol 2001, 31:2313-2318

25. von Bubnoff D, Bezold G, Matz H, Hanau D, De La Salle H, Bieber T: Quantification of indoleamine 2,3-dioxygenase gene induction in atopic and non-atopic monocytes after ligation of the high-affinity receptor for IgE. Fc(epsilon)RI and interferon-gamma stimulation. Clin Exp Immunol 2003, 132:247-253

26. Haller $\mathrm{O}$, Kochs G: Interferon-induced $\mathrm{mx}$ proteins: dynamin-like GTPases with antiviral activity. Traffic 2002, 3:710-717

27. Wenzel J, Uerlich M, Haller O, Bieber T, Tueting T: Enhanced type I interferon signaling and recruitment of chemokine receptor CXCR3expressing lymphocytes into the skin following treatment with the TLR7-agonist imiquimod. J Cutan Pathol 2005, 32:257-262

28. von Bubnoff D, Bausinger H, Matz H, Koch S, Hacker G, Takikawa O, Bieber T. Hanau D, de la Salle H: Human epidermal Langerhans cells express the immunoregulatory enzyme indoleamine 2,3-dioxygenase. J Invest Dermatol 2004, 123:298-304

29. Takikawa O, Kuroiwa T, Yamazaki F, Kido R: Mechanism of interferongamma action. Characterization of indoleamine 2,3-dioxygenase in cultured human cells inuced by interferon-gamma and evaluation of the enzyme-mediated tryptophan degradation in its anticellular activity. J Biol Chem 1988, 263:2041-2048

30. von Bubnoff D, Hanau D, Wenzel J, Takikawa O, Hall B, Koch S, Bieber T: Indoleamine 2,3-dioxygenase-expressing antigen-presenting cells and peripheral T-cell tolerance: another piece to the atopic puzzle? J Allergy Clin Immunol 2003, 112:854-860

31. Gilliet M, Conrad C, Geiges M, Cozzio A, Thurlimann W, Burg G, Nestle FO, Dummer R: Psoriasis triggered by toll-like receptor 7 agonist imiquimod in the presence of dermal plasmacytoid dendritic cell precursors. Arch Dermatol 2004, 140:1490-1495

32. Fäh J, Pavlovic J, Burg G: Expression of MxA protein in inflammatory dermatoses. J Histochem Cytochem 1995, 43:47-52

33. Sedlmayr P, Blaschitz A, Wintersteiger R, Semlitsch M, Hammer A, Mackenzie CR, Walcher W, Reich O, Takikawa O, Dohr G: Localization of indoleamine 2,3-dioxygenase in human female reproductive organs and the placenta. Mol Hum Reprod 2002, 8:385-391

34. Nguyen VT, Benveniste EN: Critical role of tumor necrosis factoralpha and NF-kappa B in interferon-gamma-induced CD40 expression in microglia/macrophages. J Biol Chem 2002, 277:13796-13803

35. Rogge L, D'Ambrosio D, Biffi M, Penna G, Minetti LJ, Presky DH, Adorini L, Sinigaglia F: The role of Stat 4 in species-specific regulation of Th cell development by type I IFNs. J Immunol 1998, 161:6567-6574

36. Puccetti P: On watching the watchers: IDO and type I/II IFN. Eur J Immunol 2007, 37:876-879

37. Manlapat AK, Kahler DJ, Chandler PR, Munn DH, Mellor AL: Cellautonomous control of interferon type I expression by indoleamine 2,3-dioxygenase in regulatory CD19+ dendritic cells. Eur J Immunol 2007, 37:1064-1071

38. Grohmann U, Fallarino F, Bianchi R, Orabona C, Vacca C, Fioretti MC, Puccetti P: A defect in tryptophan catabolism impairs tolerance in nonobese diabetic mice. J Exp Med 2003, 198:153-160

39. von Bubnoff D, Fimmers R, Bogdanow M, Matz H, Koch S, Bieber T: Asymptomatic atopy is associated with increased indoleamine 2,3dioxygenase activity and interleukin-10 production during seasonal allergen exposure. Clin Exp Allergy 2004, 34:1056-1063

40. Schroecksnadel K, Zangerle R, Bellmann-Weiler R, Garimorth K, Weiss G, Fuchs D: Indoleamine-2,3-dioxygenase and other interferon-gamma-mediated pathways in patients with human immunodeficiency virus infection. Curr Drug Metab 2007, 8:225-236

41. Takaoka A, Yanai $\mathrm{H}$ : Interferon signalling network in innate defence. Cell Microbiol 2006, 8:907-922

42. Widner B, Sepp N, Kowald E, Ortner U, Wirleitner B, Fritsch P Baier-Bitterlich G, Fuchs D: Enhanced tryptophan degradation in systemic lupus erythematosus. Immunobiology 2000, 201:621-630

43. Grohmann U, Volpi C, Fallarino F, Bozza S, Bianchi R, Vacca C, Orabona C, Belladonna ML, Ayroldi E, Nocentini G, Boon L, Bistoni F, Fioretti MC, Romani L, Riccardi C, Puccetti P: Reverse signaling through GITR ligand enables dexamethasone to activate IDO in allergy. Nat Med 2007, 13:579-586

44. Morelli AE, Thomson AW: Tolerogenic dendritic cells and the quest for transplant tolerance. Nat Rev Immunol 2007, 7:610-621

45. Fallarino F, Asselin-Paturel C, Vacca C, Bianchi R, Gizzi S, Fioretti MC, Trinchieri G, Grohmann U, Puccetti P: Murine plasmacytoid dendritic cells initiate the immunosuppressive pathway of tryptophan catabolism in response to CD200 receptor engagement. J Immunol 2004, 173:3748-3754 